\title{
Eyewitness accuracy: A general observational skill?
}

\author{
ROBERT BOICE, C. PATRICIA HANLEY, PETER SHAUGHNESSY, \\ and DAVID GANSLER \\ State University of New York, Albany, New York 12222
}

\begin{abstract}
One hundred and twenty subjects observed a videotaped scenario of a purse-snatching and, 26 min later, were asked to identify the thief from a line-up of subjects. The 60 subjects who performed difficult observational tasks during the interval between witnessing and recalling were better at making correct identifications than were 60 subjects who engaged in easy observational tasks during the same interval. Subjects who excelled as observers in a battery of general observational tests also tended to be more accurate in recalling details of the crime scene.
\end{abstract}

Documentation abounds for the unreliability of eyewitnesses and for the conditions that further diminish their already mediocre performance. Accuracy was shown to decrease when witnesses were exposed to conditions of emotional arousal (Clifford \& Scott, 1978), to delays up to $30 \mathrm{~min}$ (Sanders \& Warnick, 1980), and to hypnosis (Putnam, 1979). Except for indications that accuracy is enhanced by preexposure to the person or condition to be identified (Sanders \& Warnick, 1980), little is known about factors that facilitate or endorse the reliability of eyewitnesses.

One possibility for facilitation may be derived from Erdelyi's work on hypermnesia with visual events (Erdelyi \& Kleinbard, 1978). In his view, the increase in recall that accrues over time and with the interpolation of thinking is the result of cognitions that promote faster location and recognition of items stored in memory. Thus, imperfect recall may reflect the lack of opportunity to search and generate enough material. The implication in Erdelyi's conclusions is that cognitive conditions that encourage thinking and recall might also facilitate eyewitness accuracy. A similar suggestion has been made by Mueller, Carlomusto, and Goldstein (1978); deep, as opposed to superficial, processing improves retention. Indeed, when a "guided memory" procedure has been used with eyewitnesses, the result seems to have been the opportunity for subjects to rehearse their recollections and, accordingly, to increase their identification accuracy (Malpass \& Devine, 1981).

A second possibility is that eyewitness identification is an observational skill much like that demanded in other situations. If so, the testimony of an eyewitness might be corroborated with evidence that he or she scored highly on a battery of general observational skills. While this idea has not yet been tested directly, its collateral evidence is not promising: When, for

We thank Glenn S. Sanders for valuable suggestions and criticisms in the preparation of this manuscript. example, supposed experts such as police have been tested for eyewitness accuracy, they have not supported the notion that training is facilitative (Loftus, 1979; Yarmey, 1979). But to dismiss eyewitness accuracy as unteachable is to relegate it to the domain of the mystical (Boice, in press).

The present study is an attempt to demonstrate both possibilities of facilitating eyewitness testimony: to show that eyewitness accuracy may be enhanced by embedding the recall task in the midst of unrelated and demanding observational tasks and that the accuracy of an eyewitness might be verified against performance in a more general battery of observation tests.

\section{METHOD}

\section{Subjects}

Subjects were 120 introductory psychology students, 60 of them males, at a large state university, who participated for course credit.

\section{Observational Tests}

Eyewitness accuracy test. The eyewitness accuracy test was modeled after that of Sanders and Warnick (1980). Briefly, this test consisted of a 15-sec videotaped scenario of a "pursesnatching," followed $26 \mathrm{~min}$ later by a 40 -sec videotaped presentation of a "line-up" with four suspects, including the thief. During the interval between viewing the purse-snatching and the line-up, all subjects participated in a series of general observational tests. The line-up comprised four $10-\mathrm{sec}$ presentations of suspects presented in frontal and profile views. All four suspects were similar in age, weight, skin coloring, and hair coloring. The third of these four suspects was always the thief seen in the purse-snatching. Subjects did not have the option of indicating that the thief was not in the line-up.

After making an identification from the line-up, subjects answered 12 multiple-choice (four-foil) questions about the purse-snatching scenario. Six of those questions concerned the actions of the thief and victim; six tested for memory of physical qualities.

General observational test battery. Two forms of the general observational test battery were administered. One of moderate difficulty was first given to 60 subjects. Then, an item analysis of the first battery was used to construct a highly difficult form given to a second group of 60 subjects. 
Two basic observational contexts were chosen as meaningful for college students: a classroom lecture and a casual request for a date. Multiple-choice questions about the videotaped lecture $(6.5 \mathrm{~min})$ and the social interaction $(6.5 \mathrm{~min})$ were equally distributed in terms of verbal content, of nonverbal behaviors, and of physical appearance.

Item analysis of the questions in the first application showed that all but one or two questions per eight-question subsection exceeded a criterion of easiness (i.e., at least $55 \%$ of subjects got the item correct). In each of those questions exceeding criterion, difficulty levels were increased by rewriting questions and making the discrimination of the correct foil much more difficult.

Listening test. After subjects had completed the general observational and eyewitness tests, all 120 of them took the Jones-Mohr Listening Test (Mohr \& Jones, 1976). It consists of 30 audio-taped statements, each followed by a 10-sec period for selection of the speaker's intended emotional message.

\section{RESULTS}

\section{Eyewitness Accuracy}

Overall accuracy of these eyewitnesses was $25 \%$. Males and females performed in equivalent fashion ( 16 of 60 correct vs. $14 / 60$, respectively). But embedding that demanding identification task within the context of a series of difficult observational tasks accompanied a nearly twofold increase in eyewitness accuracy (11 of 60 correct in moderate context vs. 19/60 in demanding context).

Observational and listening tests. Overall, females performed only slightly better than did males [57\% vs. $54 \%$ correct, respectively; $F(1,116)=3.05, p<.1]$. Females did, however, excel significantly on all three subtests dealing with the social interaction and on the subtest dealing with the purse-snatching. Males performed significantly better on the verbal content subtest of the lecture $[F(1,116)=3.9, p<.05]$. On the other subtests of the lecture and on the listening test, performance was virtually identical across sexes.

Not surprisingly, the increase in difficulty of questions in the six general observational subtests and in the test about details of the purse-snatching produced a clear decrease in accuracy [67\% vs. $47 \%$, respectively; $\mathrm{F}(1,116)=185.6, \mathrm{p}<.001]$. Performance on the listening test (which was administered in identical form to all subjects) was virtually the same for both groups of subjects.

Eyewitness accuracy compared to other tests of observational accuracy. The results of an exploratory factor analysis (BMD-P4M, double-precision version) of all but the line-up identification test indicated two factors, one that can be labeled "general observational skills" and a second that might be called "listening-foraffect skill."

The interrelatedness of the other tests with that based on the eyewitness accuracy scenario may be seen in Table 1. This multiple correlational analysis indicates that on all but the listening test, subjects who correctly recalled information about the purse-snatching also
Table 1

Multiple Correlational Analysis of the Nine Observational Tests

\begin{tabular}{lcrc}
\multicolumn{1}{c}{ Test } & \multicolumn{1}{c}{$\mathrm{r}^{\mathrm{d}}$} & F Value* & $\mathrm{p}$ Value \\
\hline Verbal Content (L) & .158 & 2.63 & .025 \\
Physical Appearance (L) & .278 & 5.38 & .001 \\
Nonverbal Behavior (L) & .515 & 14.54 & .001 \\
Verbal Content (HI) & .370 & 8.07 & .001 \\
Physical Appearance (HI) & .491 & 13.26 & .001 \\
Nonverbal Behavior (HI) & .392 & 8.91 & .001 \\
Purse Snatching & .250 & 4.63 & .001 \\
Jones-Mohr Listening Test & .043 & .63 & \\
\hline
\end{tabular}

Note $-L=$ Lecture $; \mathrm{HI}=$ Heterosocial Interaction . $* d f s=7,112$.

tended to excel on other tests of observational accuracy.

Performance on the line-up identification tests was compared to that in the nine tests just mentioned by means of a point-biserial correlation. Correctness in picking the thief from a line-up of four suspects correlated positively and significantly with performance on the multiple-choice test about the details of the pursesnatching $(\mathrm{t}=1.72, \mathrm{p}<.05)$. Skill at identifying the thief did not, however, correlate significantly with any of the other tests $(t>1, p>.25$, all tests). The small numbers of subjects who made correct identifications may have precluded meaningful comparisons of this measure with others. Or, it may be that witnesses who are good at identifying the thief were not reliable in recalling more peripheral details, and vice versa (Wells \& Leippe, 1981); thus, a correlation between the two tests of eyewitness recall could be precluded by the dissimilarity of skills involved.

\section{DISCUSSION}

Embeding the identification task in a context of demanding observations produced a sizable increase in the accurate identification of the "thief" from a line-up of suspects. And, subjects who were superior observers in a general battery of observational tests also tended to excel at recalling the details of the crime scene. Thus, the likelihood of eliciting correct eyewitness testimony might be enhanced by embedding the identification in certain other identification tasks and by confirming the more general observational skill of the witness.

The finding that observational skill might be so general as to include eyewitness accuracy also has little clear precedent; there have been few systematic attempts to assess the generality of any aspect of observation. The consensus, if one may be drawn at all, is that observational skills are both general and specific across kinds of tasks; the better the observer, the more general will be the skill (Boice, in press). As in other areas of the search for good observers, research on eyewitnesses has heretofore emphasized personality traits. So, for instance, introversion/ extroversion scores did not seem to correlate with eyewitness accuracy (e.g., Clifford \& Scott, 1978). The possibility of progress in the present study may lie with the switch from personality traits to observational skills as correlates of good eyewitness performance. Why not assume, for example, that the same use of imagery and of associative networks that characterize people with excellent memories in other situations (Yarmey, 1979) also would aid an eyewitness? 


\section{REFERENCES}

Boice, R. Observational skills. Psychological Bulletin, in press. Clifford, B. R., \& ScotT, J. Individual and situational factors in eyewitness testimony. Journal of Applied Psychology, 1978, 63, 352-359.

Erdelyi, M. H., \& Kleinbard, J. Has Ebbinghaus decayed with time?: The growth of recall (hypermnesia) over days. Journal of Experimental Psychology, 1978, 4, $275-289$.

LofTus, E. F. Eyewitness testimony. Cambridge, Mass: Harvard University Press, 1979.

Malpass, R. S., \& Devine, P. G. Guided memory in eyewitness identification. Journal of Applied Psychology, 1981, 66, 343-350.

Mohr, J. E., \& Jones, L. The Jones-Mohr listening test. San Diego: University Associates Publishers \& Consultants, 1976.
Mueller, J. H., Carlomusto, M., \& Goldstein, A. G. Orienting task and study time in facial recognition. Bulletin of the Psychonomic Society, 1978, 11, 313-316.

Putnam, W. H. Hypnosis and distortions in eyewitness memory. International Journal of Clinical and Experimental Hypnosis, $1979,27,437-438$.

Sanders, G. S., \& Warnick, D. Some conditions maximizing eyewitness accuracy: A learning/memory model. Journal of Criminal Justice, 1980, 8, 395-403.

Wells, G. L., \& LeipPe, M. R. How do triers of fact infer the accuracy of eyewitness identifications? Journal of Applied Psychology, 1981, 66, 682-687.

YARMEY, A. D. The psychology of eyewitness testimony. New York: Free Press, 1979.

(Received for publication September 3, 1982.) 